\title{
Títulos e macroestruturas textuais
}

\author{
Hércules Tolêdo Corrêa \\ Centro Universitário de Belo Horizonte - UNI-BH
}

\section{Abstract}

This study has the objective of verifying how university students understand the same newspaper text from the absence $\mathrm{x}$ presence of different kinds of titles as well as questions previous to the reading. The starting point was the classification of the titles as canonic and skewed: the first are those that carry the most important information of the text, its main idea, working as a kind of summary of the summary; the latter are those that promote information of less importance to the category of the main idea of the text.

A pre-experiment was carried out with the aim of verifying the hypothesis that a given title expressed the global macroproposition of a text, thus constituting a canonic title. After that an experiment with seventy-five (75) students of the Language Course at a private college in Belo Horizonte was undertaken with the objective of verifying the extent of influence of the titles of different kinds and the initial questions in the understanding, acting on the construction of macropropositions and macrostructures.

The results of the experiment showed that the titles and the initial questions influence the construction of textual macrostructure systematically, that leads to different interpretations of the same text. Canonic and skewed titles and the presence $\mathrm{x}$ absence of titles and initial questions alter the interpretation of the same text in different ways. 
"Quer se trate de um jornal ou de Proust, o texto não tem significação a não ser através de seus leitores." (Michel de Certeau, 1990:247)

$\boldsymbol{E}$ ste trabalho teve como objetivo verificar como alunos universitários compreendem um mesmo texto jornalístico a partir da ausência $x$ presença de títulos de tipos diferentes, bem como de perguntas anteriores à leitura. Partiu-se da classificação dos títulos como canônicos e enviesados: os primeiros são aqueles que trazem a informação mais importante do texto, a sua idéia central, funcionando como uma espécie de resumo do resumo desse texto; os últimos são aqueles que promovem uma informação de menor importância à categoria de idéia central do texto.

O artigo está dividido em três partes: na primeira, apresentase um modelo psicolingüístico do processo de leitura; na segunda parte, apresenta-se o papel do título na compreensão textual e, na terceira parte, apresentam-se e discutem-se os principais resultados de uma pesquisa experimental.

\section{UM MODELO PSICOLINGÜÍSTICO DE LEITURA}

A leitura, enquanto prática social e escolar, vem sendo estudada por diversas áreas do conhecimento, como a Lingüística, a Psicologia, as Ciências Cognitivas, a Pedagogia, a História, a Sociologia. Conforme o foco da pesquisa de cada um desses campos teóricos, a concepção de leitura se modifica. Essa variação de concepções vincula-se à especialização da pesquisa, ao progresso científico e ao surgimento de novos paradigmas. Aqui, foram priorizados os trabalhos realizados na perspectiva da Psicolingüística. 
Antes das teorias de Noam Chomsky, a Lingüística tendia a ser uma espécie de "botânica verbal", ou seja, preocupava-se em coletar enunciados e classificá-los, sem que fosse feito um estudo sobre a origem desses dados e sobre os processos mentais geradores e receptores. Com Chomsky, estabelece-se uma área interdisciplinar entre a Lingüística, propriamente dita, e a Psicologia Cognitiva, fundamentando-se a Psicolingüística (CARSTON, 1988). Assim, os estudos da linguagem passam a se preocupar mais com a língua internalizada do que com a língua externalizada, ou seja, a preocupação desloca-se do produto do comportamento lingüístico para os mecanismos mentais responsáveis por esse comportamento (CHOMSKY, 1986).

O processamento de informações ocorre em dois sentidos: as informações que são percebidas pelos indivíduos (inputs) e aquelas que são produzidas (outputs). Um dos tipos de informação processada pelo sistema cognitivo humano é a linguagem verbal, o mais complexo sistema de linguagem de todos os seres vivos. O processamento da linguagem verbal envolve mecanismos de produção, como a fala e a escrita, e de recepção, como a audição e a leitura. Conforme FODOR (1983), há dois dispositivos que participam do processamento da linguagem: o módulo lingüístico e o processador cognitivo geral.

O módulo lingüístico relaciona-se com o que Chomsky chamou de língua internalizada ou gramática implícita. Resumidamente, tem as seguintes características: é automático e inconsciente, pois independe da vontade do indivíduo; é rápido (identificar, por exemplo, uma palavra ou uma frase da língua é um processo psicológico que gasta pouco tempo); é específico; é geneticamente determinado; é sistemático; é limitado na capacidade.

Já o processador cognitivo geral é tido como um dispositivo com características inversas às características dos módulos: não é automático, ou seja, é pensado; é relativamente lento, em comparação com os módulos; é mais geral, não relacionado a determinado tipo de estímulo; é opcional e acessível quando se deseja; é muito mais determinado pelo meio; varia de indivíduo para indivíduo; é ilimitado na capacidade. 
Como já foi dito, a leitura é um processo complexo e, portanto, exige o uso dos dois dispositivos acima propostos. Em cada um deles, ainda, é possível perceber uma subdivisão. É importante falar de cada um desses domínios separadamente.

\subsection{O reconhecimento de palavras ou acesso lexical}

Neste domínio, os rabiscos são reconhecidos como letras e conjuntos de letras são reconhecidos como palavras de uma língua ou como não-palavras. Ao se reconhecer uma palavra, vários tipos de informação são ativados, como a grafia, a forma fonológica e o significado. Pesquisas experimentais já mostraram que o tempo gasto no reconhecimento de uma palavra depende da sua extensão quanto maior, mais tempo gasto - e da sua freqüência - palavras mais vistas são mais facilmente reconhecíveis. Também o contexto tem importância, nessa etapa, uma vez que, através dele, é possível selecionar um significado em vez de outro (sobre essas pesquisas, ver, por exemplo, EYSENCK \& KEANE, 1994).

O reconhecimento de palavras pertence ao módulo lingüístico e é, por isso, automático, rápido e inconsciente. Se se é alfabetizado, lêem-se as palavras vistas independentemente da vontade, a menos que se tenha a atenção desviada (COSCARELLI, 1993).

\subsection{A identificação de estruturas sintáticas}

Durante a leitura, após o reconhecimento de palavras, o leitor identifica, nos enunciados que constituem o texto, as estruturas sintáticas. Neste domínio, o leitor distingue frases gramaticais de frases agramaticais, conforme o seu conhecimento da estrutura da língua usada.

MITCHELL (1987) postula que a identificação de estruturas sintáticas, também conhecida como parsing sintático, seja constituída de dois estágios diferentes: 1) a escolha da hipótese preliminar ou adivinhação; 2) a decisão de revisar ou abandonar uma hipótese a partir de outra. Para as frases ambíguas, parece ser neste segundo 
estágio que o leitor opta por uma das interpretações possíveis, com base no contexto e nos seus conhecimentos prévios.

Para os autores que vêem a leitura apenas como 'decodificação' de sinais gráficos e organização das estruturas sintáticas, o processo termina neste ponto. O processamento é visto como meramente modular, sem utilização de raciocínios mais complexos, como a geração de inferências, o estabelecimento de relações entre diversos textos, a utilização de conhecimentos prévios, etc.

\subsection{A produção de significados ou interpretação semântica}

Alguns teóricos postulam que a estrutura sintática e a análise semântica (produção de significados) sejam conduzidas independentemente, enquanto outros dizem que esses aspectos são processados ao mesmo tempo. Estudos sugerem que as pessoas se esforçam para compreender o significado da frase o mais rápido possível; então, a estrutura superficial é descartada e permanece o significado, ou seja, a memória de longo termo guarda as proposições e não as estruturas lingüísticas (ver, por exemplo, WINGFIELD, 1993). Em geral, passado algum tempo, o que "sobra" da leitura é o significado e não mais a forma literal.

\section{Inferências}

Além das informações explícitas no texto, outras proposições são geradas através de inferências, que são processos cognitivos através dos quais uma informação nova surge a partir de uma informação anterior, em um determinado contexto. Essas inferências constituem a participação dos conhecimentos do leitor na leitura. Desta etapa em diante, o texto perde um pouco a sua importância para se dar maior importância aos conhecimentos prévios do leitor. As inferências ocorrem também quando o leitor busca fora do texto informações e conhecimentos adquiridos pela sua experiência, com os quais preenche os "vazios" textuais. O leitor traz para o texto um universo individual que interfere na sua leitura, uma vez que extrai inferências determinadas por seu "eu" psicológico e social (DELL'ISOLA, 
1988). É importante frisar que as inferências não estão no texto, uma vez que são processos cognitivos: o texto existe, o leitor infere.

\subsection{A construção de macroestruturas}

Desta etapa em diante a compreensão depende basicamente do processador cognitivo geral. A partir das proposições geradas na interpretação semântica - tanto aquelas originadas das informações explícitas, quanto as originadas das inferências - o leitor tenta constituir a coerência global do texto. Assim, a partir de proposições, formam-se as macroproposições de diversos níveis, construindo-se a macroestrutura textual.

\section{Macroestruturas}

Hoje em dia, define-se o texto como uma unidade semântica em que os vários aspectos da significação são materializados através de categorias lexicais, sintáticas, semânticas e estruturais. Dessa forma, parece que o que define mesmo um texto é a noção de unidade, composta de várias outras unidades menores ou subunidades de sentido chamadas proposições. O conjunto de proposições de um texto aparece na superfície, previamente sinalizada pelo autor, como um conjunto de frases que se relacionam constituindo um todo semântico.

É essa idéia de um todo semântico que permite a noção de macroestrutura textual. Proposições lineares e seqüenciais se agrupam numa proposição de nível superior, que pode ser inferida durante a leitura - uma abstração feita pelo leitor - para constituir uma macroproposição.

Conforme VAN DIJK \& KINTSCH (1983), a construção das macroproposições se dá através de três macrorregras, que transformam a informação semântica, reduzindo, abstraindo e, ao mesmo tempo, hierarquizando o conteúdo proposicional:

1. Apagamento - dada uma seqüência de proposições, aquelas que são secundárias podem ser apagadas (ou, numa analogia com o 
jargão informático, deletadas). Por exemplo: a seqüência Uma senhora elegantemente vestida com um conjunto preto e branco entrou numa joalheria de um dos shoppings mais elegantes da cidade e assaltou a loja com um revólver de brinquedo poderia ser resumida em Senhora elegante assalta joalheria, em que várias informações consideradas secundárias são eliminadas, permanecendo apenas aquelas consideradas fundamentais para a expressão do conteúdo macroproposicional.

2. Generalização - proposições específicas podem ser reunidas em uma proposição mais generalizada. Por exemplo, Tomar um ônibus da viação Cometa até São Paulo pode ser generalizado na macroproposição Viajar.

3. Construção: uma nova proposição pode ser construída, contendo uma informação abstraída da seqüência de proposições original. Por exemplo, as proposições Comprarpassagem; Ir até o terminal rodoviário e Tomar o ônibus podem ser agrupadas numa macroproposição mais genérica que seria: Viajar de ônibus ou, num outro exemplo, Namorar pode ser uma macroproposição genérica de proposições do tipo: Olhar apaixonadamente um para o outro, Ir ao cinema abraçados, Comer pipocas juntos.

As macroproposições de um texto constituem conceitos relativos, uma vez que, estabelecidas as macroproposições de primeiro nível, estas se agrupam para formar outras de segundo nível e assim por diante. A macroproposição global é aquela proposição que, construída através das macrorregras acima referidas, representa o conteúdo geral do texto ou sua idéia central. As macroproposições de níveis hierárquicos inferiores à global são chamadas de macroproposições locais, e o conjunto, tanto os nódulos globais quanto os locais, é chamado de macroestrutura textual.

Em linguagem mais próxima da sala de aula, pode-se dizer que a macroproposição global do texto corresponde ao tópico central, tema, conteúdo global ou idéia central do texto. As macroproposições locais são os tópicos secundários ou as várias idéias centrais de cada uma das partes do texto. 
A capacidade de construção da macroestrutura textual, enquanto indicador do estabelecimento da coerência global, constitui um índice da capacidade de compreensão de um texto, em seus aspectos globais.

Pesquisas realizadas por TERZI (1995) e LOBATO (1993 e 1995) utilizam a noção de macroestrutura textual para observar a capacidade de compreensão de alunos alfabetizandos, de pós-graduação e de segundo grau, respectivamente. As três pesquisas realizadas apontam para a dificuldade que os sujeitos têm, nos três níveis, na construção da macroestrutura textual, o que os leva a construírem macroestruturas diferentes daquelas sinalizadas no texto. A esse "defeito" de leitura, as autoras chamaram de "processo de apropriação do texto". As autoras justificam essa terminologia, baseando-se no fato de que os sujeitos, ao terem dificuldade de captar a macroestrutura sinalizada pelo autor, constroem a sua própria, de diferentes maneiras, a partir da reformulação das informações textuais e como resultado da transformação de uma macroproposição local em global, por exemplo. Isso gera uma leitura "inadequada".

Entretanto, é preciso levar em conta que um mesmo texto pode gerar diferentes macroestruturas, conforme seu leitor, sem que essas sejam consideradas inadequadas. A possibilidade de variação existe e precisa ser considerada, uma vez que se tem como pressuposto $a$ construção do sentido pelo leitor e não apenas a reconstrução do sentido sinalizado pelo autor. Essa diferença possível entre as várias macroestruturas de um mesmo texto justifica-se pela natureza estratégica da construção do tema do texto, influenciada por fatores como: 1) eficiência em leitura dos sujeitos-leitores; 2) os aspectos sociais da construção de sentido do texto (atitudes, crenças, valores, enfim, todo o conhecimento prévio do leitor); 3) os aspectos lingüísticos do texto.

\section{Superestruturas}

Além dessa macroestrutura de ordem temática, os textos em geral comportam formas esquemáticas convencionais chamadas 
superestruturas. Assim como se propõe uma sintaxe para a frase, com estruturas típicas, propõe-se uma macrossintaxe para o texto.

As superestruturas devem ser vistas como elementos de natureza cognitiva culturalmente organizadas na memória, em forma de modelos de diferentes tipos de textos. Portanto, elas não são universais, mas culturalmente dependentes.

Textos argumentativos têm superestruturas típicas tais como o silogismo, descrito pela Lógica, constituído de diferentes tipos de premissas e uma conclusão. Um outro modelo de argumentação, descrito por VAN EEMEREN \& GROOTENDORST (1984), traz a seguinte superestrutura: (1) Abertura; (2) Argumentação, subdividida em três partes: Formulação da tese, Posicionamento, Suporte - este último, constituído de evidências; e (3) Conclusão.

As narrativas têm uma superestrutura típica constituída de cinco partes, a saber, apresentação ou situação (setting), complicação, resolução, avaliação e conclusão ( coda) (LABOV \& WALETSKY, 1967).

Essas superestruturas típicas constituem apenas uma exemplificação de muitas das possibilidades oferecidas pela literatura. Há muitos modelos de textos argumentativos, narrativos, dentre outros, embora, em geral, essas superestruturas se aproximem em diversos pontos.

\section{Conhecimentos prévios}

Os conhecimentos prévios do leitor passaram a desempenhar um papel fundamental no ato de ler, a partir das concepções de leitura que priorizam a relação texto-leitor, uma das principais contribuições da Psicolingüística ao desvelamento e à descrição do processo de leitura. KLEIMAN (1989:13) afirma que "é mediante a interação de diversos níveis de conhecimento, como o conhecimento lingüístico, o textual, o conhecimento de mundo, que o leitor consegue construir o sentido do texto." Portanto, os conhecimentos prévios são as estruturas cognitivas de que dispomos e que nos auxiliam na produção e na compreensão do discurso. 
A orientação construtivista de pesquisas recentes tem enfatizado o papel do conhecimento prévio na leitura. Não apenas a falta de conhecimento sobre um assunto impede a compreensão, como a extensão do conhecimento influencia a qualidade da interpretação que um leitor pode construir.

\section{Estruturas cognitivas}

Já se sabe suficientemente sobre a leitura para se afirmar que os conhecimentos prévios a influenciam decisivamente, podendo originar leituras bastante diferentes de um mesmo texto, conforme o leitor, ou mesmo leituras diferentes de um mesmo leitor, em momentos distintos. Porém, é necessário responder a uma questão básica: como esses conhecimentos são organizados no cérebro humano?

Foi buscando respostas a essa questão que pesquisadores da Psicologia Cognitiva e da Inteligência Artificial começaram a elaborar teorias a respeito da organização do conhecimento, as quais têm despertado muito interesse na área dos estudos da linguagem. $\mathrm{O}$ termo esquema (do grego schema, plural schemata-aspecto, forma, figura) ganhou destaque na literatura das Ciências Cognitivas a partir da década de 70, muito embora já tivesse sido utilizado anteriormente por alguns estudiosos, como, por exemplo, Kant (1724-1804), Head, em 1920, e Bartlett, em 1932.

As estruturas cognitivas denominadas esquemas são fundamentais para o processamento da informação e, por conseguinte, para o processamento do discurso, tanto oral quanto escrito. Elas são empregadas nos diversos processos de interpretações perceptuais (lingüisticas e não-lingüísticas), na recuperação de informações na memória, na organização das ações, na determinação de metas, na alocação de recursos e, genericamente, no direcionamento dos resultados.

Para explicar a natureza do esquema, RUMELHART (1980) utiliza uma metáfora: o esquema é como uma peça de teatro, cujo roteiro poderá ser adaptado sem que se perca a sua essência e cujos atores e formas de representação são diferentes conforme a ocasião. 


\subsection{A integração de conhecimentos}

O conhecimento veiculado pelo texto é "captado", ao adequarse a conhecimentos armazenados na memória do leitor, no momento da atividade de compreensão, gerando a construção do sentido. Esse domínio da leitura é chamado de integração de conhecimentos. Os conhecimentos prévios, uma espécie de dicionário enciclopédico do mundo e da cultura arquivado na memória, são ativados no momento da recepção do texto, auxiliando na construção de sentidos e no estabelecimento do tema global, dentre outros aspectos.

A partir dos conhecimentos prévios e dos índices formais do texto, o leitor constrói para si uma representação mental desse texto. Essa representação mental nada mais é que uma das possíveis macroestruturas do texto, uma vez que, na maioria das vezes, o produto da leitura - a interpretação do texto - é síntese das proposições mais importantes.

Em virtude das diferenças nas estruturas cognitivas entre interlocutores, em circunstâncias reais de comunicação, o leitor pode elaborar inferências não-pretendidas e não-autorizadas pelo autor do texto, isto é, inferências ditadas não pelo conteúdo do texto, mas por ativação do conhecimento prévio do leitor sobre determinado assunto, contido em sua memória. A construção de sentido do texto, durante a leitura, estará vinculada à integração entre os conhecimentos que o leitor já possuía e as informações advindas do texto. Como esses conhecimentos variam de pessoa para pessoa, a integração de conhecimentos e a construção da macroestrutura textual poderão se dar de maneira mais ou menos diferenciada, de acordo com o leitor.

Resumidamente, o modelo psicolingüístico de leitura, conforme o estado do conhecimento atual, pressupõe os seguintes domínios de processamento:

- o reconhecimento de palavras ou acesso lexical;

- a identificação de unidades sintáticas ou parsing sintático;

- a produção de significados ou interpretação semântica;

- a construção de macroestruturas (esquemas);

- a integração de conhecimentos. 
Uma contribuição prática desse modelo psicolingüístico da leitura é uma maior possibilidade de visualização do planejamento e da execução de atividades didáticas. Como o processo está dividido em vários subprocessos, autores de manuais didáticos e professores podem elaborar atividades práticas para o ensino que enfatizem um ou outro desses subprocessos. Por exemplo, para a produção de textos que visem à questão da construção de esquemas, o psicolingüista Mike Dillinger sugere um "varal de histórias". Para a realização dessa atividade, basta fazer um varal na sala de aula, com barbante ou fio de nylon, e reservar uma parte dele para cada grupo de alunos. Os alunos deverão dependurar objetos e desenhos no varal, formando uma história. Nenhum estímulo verbal será permitido, ou seja, não se podem dependurar no varal palavras ou frases. Montado o varal, por determinado grupo, os outros grupos deverão "ler" a história contada. Para checar se a tarefa foi bem cumprida ou não, basta avaliar o grau de dificuldade que os alunos têm de contar a história montada. Se a história recontada for muito diferente da pretendida pelo grupo que a montou, é sinal de que os membros do grupo não colocaram pistas suficientes no varal/texto. Os colegas, então, deverão contribuir, sugerindo modificações na disposição, retirada e/ou acréscimo de objetos. Dessa forma, os colegas vão chegar a um acordo quanto à intenção dos autores e à interpretação dos leitores.

Uma atividade didática bastante tradicional em nossas escolas é o trabalho com o resumo de textos. Entretanto, sabe-se que muitas vezes o aluno, na verdade, não resume o texto, mas apenas "pinça" nele algumas frases, transcrevendo-as sem nem fazer as adaptações gramaticais necessárias. Pesquisas como as de TERZI (1995) e LOBATO (1993 e 1995), anteriormente citadas, confirmam essa dificuldade dos alunos na construção de resumos textuais. Trabalhar o subprocesso de construção de macroestruturas pode contribuir para a aprendizagem de tarefas como essa. Para isso, o professor não pode apenas pedir aos alunos que leiam e resumam determinado texto (de preferência um texto não-literário). O professor deve trabalhar 
sistematicamente com os alunos a leitura do texto, tendo em vista a identificação das suas idéias principais e secundárias através da compreensão, atividade eminentemente cognitiva, do que está sendo lido e do desenvolvimento da habilidade, também cognitiva, de síntese. Só assim o aluno estará apto a realizar eficientemente a tarefa de resumir textos.

Muitas outras atividades didáticas - tradicionais ou não poderiam ser discutidas neste artigo, não fosse a exigüidade de espaço. Entretanto, a partir da descrição deste modelo de leitura e da análise dos dados coletados, pode-se pensar nessas atividades, reavaliando práticas antigas e cristalizadas e criando novas práticas pedagógicas com o objeto texto.

Em suma, a maior vantagem do modelo é a possibilidade de se desdobrar o processo em subprocessos, permitindo trabalhar cada parte sem perder de vista o conjunto no qual ela se insere.

\section{O PAPEL DO TÍTULO NA LEITURA}

O título do texto jornalístico constitui a apropriação de uma forma publicitária pelo jornalismo, ou seja, a sua principal característica é chamar a atenção do leitor para o texto. O título é como um anúncio publicitário, cujo objetivo é vender seu produto: a notícia (ou outro tipo de texto qualquer publicado no jornal, como o artigo, a reportagem, a coluna, o editorial, etc.). Por seu aspecto gráfico, localizado acima do texto e impresso com tipos maiores e geralmente ocupando mais de uma coluna, ele constitui uma saliência textual. Com isso, o título ganha funções semânticas e cognitivas. Redigido depois do texto, portanto anafórico do ponto de vista da produção, o título desempenha, no processo de leitura, uma função eminentemente catafórica e, assim, exerce grande influência sobre o leitor, na medida em que funciona como estímulo ou desestímulo à leitura. O título desempenha, dessa forma, uma importante função argumentativa, pois constitui uma estratégia a serviço das intenções do enunciador que pretende influir sobre o leitor, interessá-lo e convencê-lo, numa situação real de interlocução (CORACINI, 1989:235). 
O tipo de título mais comum é aquele que representa um resumo do resumo do texto. Esse tipo, denominado canônico, expressa a macroproposição global e, portanto, o topo da macroestrutura semântica. Os títulos canônicos exercem um papel fundamental no processamento de informações expressas nos textos jornalísticos antes, durante e depois da leitura do texto em si.

Hipoteticamente, pressupõe-se que, enquanto se lê, o conteúdo proposicional do título vai funcionando como uma macroproposição, com a qual se monitora a compreensão do texto, permitindo que o leitor "descarte" as informações menos relevantes e se atenha às mais relevantes, a fim de que possa entender e armazenar, na memória de trabalho, as informações. Durante a leitura, a macroproposição monitoradora permite a interpretação de detalhes locais e/ ou ambíguos. Muitas vezes, na ausência do título, esses detalhes podem tornar difícil o estabelecimento da compreensão global dos textos.

Um outro tipo de título, denominado enviesado (skewed beadline-VAN DIJK \& KINTSCH, 1992b), é aquele em que uma proposição de nível baixo da estrutura semântica - uma macroproposição local - é promovida a tópico principal - macroproposição global -, aparecendo no título do texto. Essas macroproposições locais podem ser oriundas de qualquer um dos níveis da macroestrutura, em termos semânticos, ou de qualquer das partes da superestrutura, em termos da sua macrossintaxe.

\section{A PESQUISA EXPERIMENTAL}

Foi realizado um pré-experimento, com o objetivo de se verificar a hipótese de que determinado título expressasse a macroproposição global de um texto, constituindo, assim, um título canônico. Depois, foi realizado o experimento que se encontra abaixo delineado:

Sujeitos:

Setenta e cinco (75) alunos do primeiro período do curso de Letras de uma faculdade particular de Belo Horizonte 
- turmas do segundo semestre de 1995 e primeiro semestre de 1996 (sete grupos experimentais, com uma média de 10 sujeitos em cada um).

Materiais:

Um mesmo texto jornalístico (Anexo A) em quatro versões:

1. Sem título;

2. Com título canônico (T1) - Autoridades brasileiras parecem humoristas;

3. Com título enviesado (T2) - Banco engana banco;

4. Com título (mais) enviesado (T3) - José Simão ameaçado.

As versões 2, 3 e 4 foram apresentadas de duas formas:

1. Sem perguntas iniciais;

2. Com perguntas iniciais, referentes ao conteúdo dos títulos.

Tarefas:

Os sujeitos da pesquisa deveriam realizar as seguintes tarefas:

1. Leitura do texto;

2. Reprodução livre (free recall);

3. Reprodução dirigida (respostas a perguntas objetivas referentes a cada um dos subtópicos do texto);

4. Respostas às perguntas iniciais (apenas três grupos).

Análises:

Os dados foram trabalhados através dos seguintes processos:

1. Análise proposicional do texto;

2. Análise de processamento (reprodução literal de proposições - R, reprodução com inferência $-\mathrm{RI}$, e inferência -I);

3. Análise Multivariada de Variância. 


\section{Principais resultados e discussão}

Abaixo, são apresentados os principais resultados da pesquisa experimental. Para facilitar a leitura, discussões sucintas desses resultados foram apresentadas imediatamente.

\section{Efeitos dos grupos}

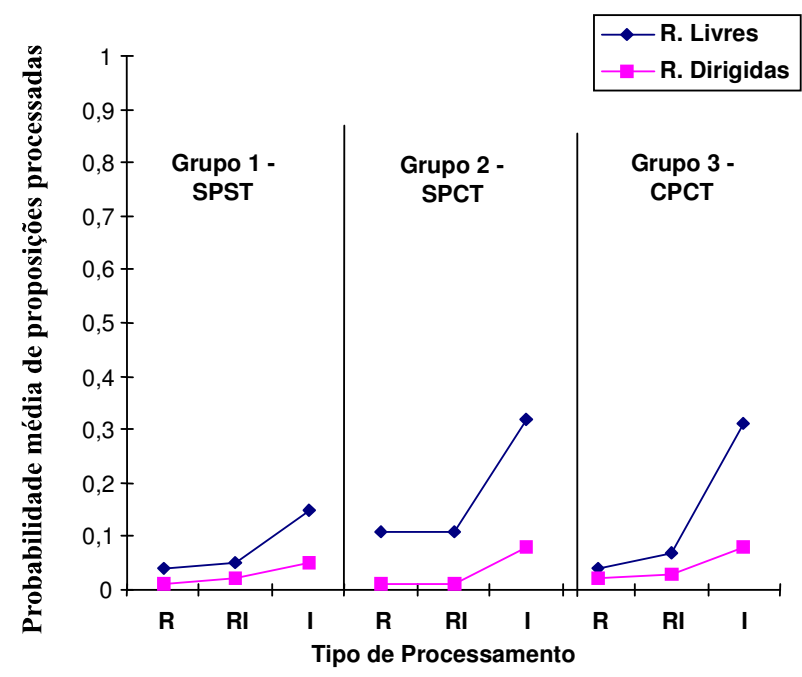

GRÁFICO 1 - Efeitos de grupos: ausência x presença de títulos e perguntas iniciais, por tipo de processamento, nas reproduções livres e dirigidas

Grupo 1 - Sujeitos que leram o texto sem perguntas e sem título Grupo 2 - Sujeitos que leram o texto sem perguntas e com títulos Grupo 3 - Sujeitos que leram o texto com perguntas e com títulos

\section{Resultados}

Na presença de títulos, aumentou a probabilidade média de processamento de reproduções, reproduções com inferências e inferências.

Na presença de perguntas iniciais, diminuiu a probabilidade média de processamento de reproduções literais e reproduções com inferências. 


\section{Discussão}

Parece que o título promove mais processamento inferencial, talvez por tornar disponíveis alguns conhecimentos prévios necessários à leitura.

Os títulos afetaram a compreensão, porque influenciaram mais justamente as inferências, nas quais a participação dos conhecimentos prévios do leitor é maior.

As perguntas iniciais inibem e/ou desestimulam o processamento literal sem interferir nas inferências, talvez por redirecionar, implicitamente, o objetivo da leitura, sugerindo que não seja apenas a reprodução fiel do texto lido. Pode ser também que as perguntas iniciais tenham desestimulado os leitores em virtude de sua semelhança com tarefas escolares, embora a escola trabalhe mais perguntas posteriores à leitura.

\section{Efeitos dos títulos}

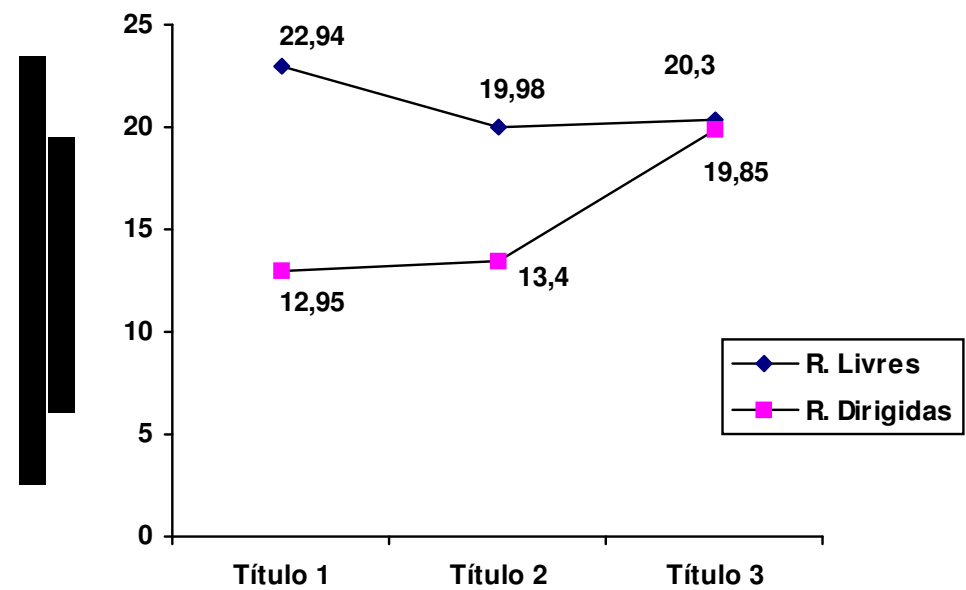

GRÁFICO 2 - Efeitos dos tipos de títulos nas reproduções livres e dirigidas. Título 1: canônico - Títulos 2 e 3: enviesados. 


\section{Resultados}

As diferenças são maiores para o Título 1 - Autoridades brasileiras parecem humoristas - diminuem um pouco para o Título 2 - Banco engana banco - e quase desaparecem para o Título 3 José Simão ameaçado.

\section{Discussão}

A reprodução dirigida parece conduzir ao processamento maior de proposições que não foram processadas espontaneamente nas reproduções livres. Assim, no caso do Título 3, parece que as perguntas das reproduções dirigidas fizeram com que se aumentasse a quantidade de proposições processadas relativas ao subtópico textual que trata da "ameaça ao José Simão", enquanto nos outros casos essas informações ficaram "perdidas" para os leitores, que não viram nelas maior importância para a compreensão global do texto.

\section{Efeitos das macroproposições}

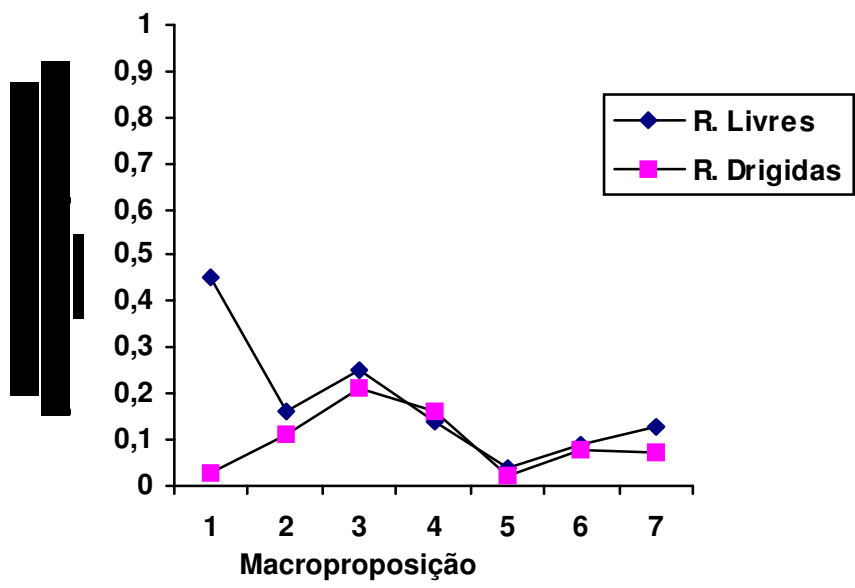

GRÁFICO 3 - Efeitos das macroproposições - sem perguntas iniciais 


\section{Resultados}

Para uma melhor compreensão das macroproposições aqui consideradas, ver o Anexo A.

Diferença maior na macroproposição 1 - O narrador apresenta a situação: sua felicidade pelo último dia de trabalho antes das férias.

Diferença entre as macroproposições ( 2 - O governo espiona o próprio governo, 3 - O governo usa mal o dinheiro público e 4 - Bancos estatais enganam um ao outro) e (5 - O presidente do Banco Central espiona seus colegas do Banco do Brasil, 6 - O narrador se oferece para uma auditoria na agência do Banco do Brasil em Madri e 7 - O narrador chega à coluna de seu ídolo, José Simão, e se decepciona com sua pouca graça naquele dia.)

\section{Discussão}

Parece que o conteúdo das macroproposições 2, 3 e 4 é mais importante para a construção da macroproposição global.

Houve baixíssima probabilidade média de processamento da macroproposição 1. Isso talvez se deva à ausência de perguntas a seu respeito nas reproduções dirigidas.

A macroproposição 7 (que veicula um conteúdo relacionado com o Título 3 - mais enviesado) obteve maior probabilidade média de processamento pelos sujeitos que leram o texto com o Título 3, na presença de perguntas iniciais. Quando se apresenta esse título, as informações do texto relacionadas a ele têm probabilidade média de processamento muito maior, o que demonstra a influência do enviesamento dos títulos nos processos de leitura. Como foi dito acima, parece que, se não aparece esse conteúdo proposicional no título, os leitores tenderão a desprezá-lo. 


\section{Efeitos dos tipos de reprodução (perguntas posteriores)}

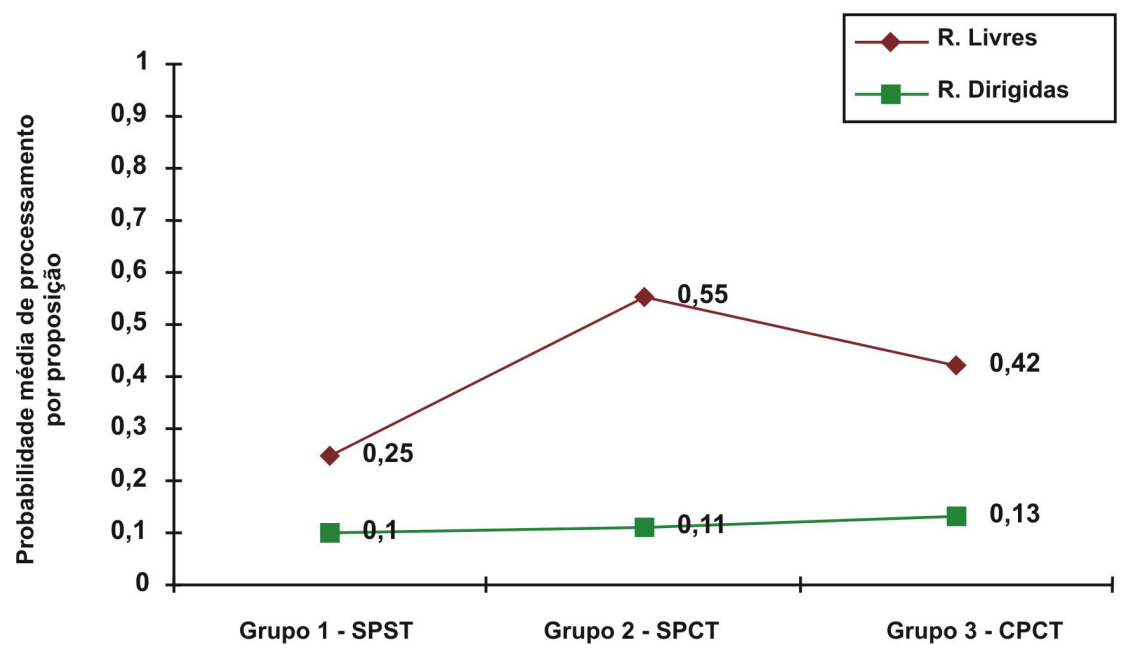

GRÁFICO 4 - Efeitos de grupos: ausência $x$ presença de títulos e perguntas iniciais nas reproduções livres e dirigidas

Observação: os grupos são os mesmos do GRÁFICO 1

\section{Resultados}

Efeitos significativos apenas nas reproduções livres.

Ausência $x$ presença do título afetou mais o processamento do que a ausência $x$ presença de perguntas iniciais.

\section{Discussão}

Os efeitos dos títulos são maiores nas reproduções livres do que nas reproduções dirigidas, tanto em termos globais quanto por tipo de processamento. 
É provável que a reprodução livre seja uma forma mais fiável de medida de compreensão do que a reprodução dirigida, quando se quer medir a influência do fator título, uma vez que dá maior liberdade de processamento por parte dos leitores. A reprodução dirigida parece inibir e/ou desestimular o processamento. É provável que a reprodução dirigida torne mais homogênea, a posteriori, a interpretação feita. Os próprios nomes dados às reproduções endossam as conclusões: reproduções livres permitem uma interpretação mais subjetiva, enquanto a reprodução dirigida parece produzir uma convergência de leituras entre os diversos sujeitos.

\section{Outros fatores relevantes}

O Título 3 (mais enviesado) - José Simão ameaçado - levou a um número maior de inferências. Isso talvez se deva ao fato de que os sujeitos tiveram que inferir mais para garantir a coerência textual, enquanto que os outros dois títulos "facilitaram" a leitura, na medida em que talvez tenham possibilitado aos sujeitos fazer um menor número de inferências.

Parece que as perguntas iniciais, ao contrário do que se pensa na prática pedagógica, têm um efeito negativo na leitura, na medida em que não modificam substancialmente a compreensão conforme a variedade de título usado. As perguntas posteriores (reprodução dirigida) parecem ter também efeito negativo, uma vez que inibem o processamento das reproduções literais e de reproduções com inferências e não aumentam as inferências. Há que se lembrar, contudo, que são perguntas objetivas e não inferenciais.

Resumindo, pode-se dizer que os resultados do experimento mostraram que os títulos e as perguntas iniciais influenciam sistematicamente a construção da macroestrutura textual, o que leva a interpretações diferentes para um mesmo texto. Títulos canônicos e enviesados a presença/ausência de títulos e de perguntas iniciais alteram de diferentes maneiras a interpretação de um mesmo texto. 


\section{Contribuições}

Abaixo, são apresentadas sucintamente algumas contribuições teóricas, metodológicas, empíricas e práticas desta pesquisa.

\section{Teórica}

- Descrição de um modelo psicolingüístico de leitura, com ênfase (detalhamento) na construção de macroestruturas textuais.

\section{Metodológicas}

- Avaliação da análise de processamento (R,RI,I), via análise proposicional do texto, como medida de compreensão de textos, em língua portuguesa.

- Avaliação da relevância da Análise Multivariada de Variância MANOVA - como forma de se detectarem as diferenças estatisticamente significativas.

\section{Empíricas}

- Levantamento sistemático de dados, em língua portuguesa, com um grupo de sujeitos, sobre:

- a leitura de alunos recém-ingressos no curso superior,

- a leitura de um texto jornalístico de opinião,

- os efeitos de títulos, em geral, na leitura,

- os efeitos de títulos na leitura de um texto jornalístico de opinião,

- os efeitos de perguntas iniciais na leitura,

- os efeitos de perguntas posteriores na leitura.

\section{Práticas}

- Os dados da pesquisa podem constituir subsídios para trabalho didático-pedagógico a partir do modelo teórico descrito com textos jornalísticos de opinião; com títulos e com perguntas anteriores e posteriores à leitura; 
- Os dados também podem constituir subsídios teóricos e sistemáticos para produtores de textos e de títulos em geral, para profissionais de diversas áreas, como redatores, jornalistas, autores de material didático-pedagógico, etc.

\section{Pesquisas futuras}

Os resultados da presente pesquisa apontam para a possibilidade de realização de trabalhos como a investigação das relações entre o conteúdo proposicional dos títulos e o conteúdo dos textos, bem como o aproveitamento desse conteúdo na leitura Apontam, também, para a necessidade de elaboração de uma classificação mais rigorosa dos tipos de títulos, com relação à sua função na construção da macroestrutura textual. Um outro ponto importante a ser investigado são os processos de construção de macroproposições e macroestruturas, bem como o uso das macrorregras. São importantes, ainda, pesquisas para avaliar as causas (inibição/desmotivação - redirecionamento dos objetivos) da alteração do processamento inferencial na presença de perguntas iniciais.

Concluindo este trabalho, é interessante lembrar que a palavra ler, do latim legere, numa primeira instância, significava contar, enumerar as letras; em seguida, significava colher e, por último, roubar. A palavra traduz, em sua raiz, três níveis de leitura: 1) a leitura enquanto decodificação ou decifração (a soletração, a vocalização de sinais gráficos, o agrupamento de letras em sílabas e palavras); 2) a leitura enquanto "colheita", por parte do leitor, do sentido já pronto no texto, demarcado unicamente pelas intenções do autor e 3) a leitura enquanto construção do sentido por parte do leitor, na medida em que roubar traz uma idéia de subversão, de clandestinidade. Não se rouba algo com o consentimento do proprietário. Assim, a leitura é, metaforicamente, um roubo por parte do leitor, uma apropriação de um bem (WALTY,1995). E, como diz Michel de Certeau: "Bem longe de serem escritores, fundadores de um lugar próprio (...), os leitores são viajantes; eles circulam sobre as terras de outrem, caçam, furtivamente, como nômades através de campos que não escreveram." (CERTEAU, 1990:251) 


\section{ANEXO A}

São Paulo - Abro a Folha feliz da vida. É sexta-feira, último dia de trabalho antes de uma semana de férias. O bom humor aumenta ao chegar à página 1-5 e ao título "Jatene prova que governo 'escondia' dinheiro e leva sobras para Saúde".

Lembro-me de "Spy $x$ Spy", a melhor das tiras da revista satírica "Mad". O governo espionando o governo para ver onde o governo esconde dinheiro do governo. Formidável. Se a moda pega, imagine o Sérgio Motta, com aquele corpinho de miss, escondido atrás das cortinas do Planejamento para ver o Serra contando o dinheiro dos impostos do dia.

Passo para a 1-7 e meu humor se transforma em incontido orgulho cívico. "Planalto usa FSE para comprar goiabada", diz o título. Que beleza. Pode não ser um investimento social, mas que é de extremo bom gosto, lá isso é. Ainda mais que se trata de goiabada cascão.

Só me irrita um pouco o tom crítico do texto. A reportagem diz que o Ministro das Comunicações comprou tampa de vaso sanitário com dinheiro do Fundo Social de Emergência. Por que a crítica? Há algo de mais fundo e de maior emergência do que vaso sanitário?

Passo para o caderno 2. Na página 7, está: "BB dribla limite de três meses no crédito". É a informação de que a agência de Brasília do BB financia carros em seis meses, o dobro do prazo permitido pelo Banco Central.

Distraído, cabeça meio em férias, penso: banqueiro é fogo mesmo. Vive inventando um jeito de passar a perna um no outro. Só depois me lembro que BB e BC são ambos bancos estatais. Deveriam atuar em conjunto e não passar a perna um no outro.

Já imaginou se o Pérsio Arida, o presidente do BC, resolve espionar, como Jatene, seus colegas do BB? Ô, Pérsio, se precisar de uma mãozinha, me ofereço para uma auditoria independente na agência da calle Serrano em Madri. Não entendo nada de banco, mas Madri é comigo mesmo.

O estado de espírito feliz sofre um baque ao chegar à coluna do meu ídolo José Simão. Estava meio sem-graça ontem. Deve ser o efeito de tanta concorrência desleal. Zé, cuidado que, nesse ritmo, os homens ainda vão tomar o teu emprego. 


\section{NOTA}

* Este artigo é um resumo da dissertação de mestrado intitulada Processos de leitura: a influência do título na construção de macroestruturas textuais, defendida no Curso de Pós-Graduação em Estudos Lingüísticos da Faculdade de Letras da UFMG, em 13 de dezembro de 1996, sob a orientação do Professor Doutor Mike Dillinger.

\section{REFERÊNCIAS BIBLIOGRÁFICAS}

CARSTON, Robyn. Language and cognition. In: NEWMEYER, F. J. (Ed.) Linguistics: the Cambridge survey, v.3: Language: psychological and biological aspects. Cambridge: Cambridge University Press, 1988.

CHOMSKY, Noam. Knowledge of language: its nature, origin, and use. New York: Praeger Publishers, 1986.

CERTEAU, Michel de. L'Ivention du quotidien, I (Arts de faire). Paris: Gallimard, 1990.

COSCARELLI, Carla V. A leitura dos elementos coesivos nominais na 1a. série. Belo Horizonte: Faculdade de Letras da UFMG, 1993. (Dissertação, Mestrado em Letras: Estudos Lingüísticos).

CORACINI, Maria José R. Faria. O título: uma unidade subjetiva (caracterização e aprendizagem). Trabalhos de Lingüistica Aplicada. Campinas (13), jan./ jun., 1989. p. 235-254.

DELL'ISOLA, Regina Lúcia Péret. Leitura: inferências e contexto sócio-cultural. Belo Horizonte: UFMG, 1988.

EYSENCK, M. W., KEANE, M. T. Psicologia cognitiva: um manual introdutório. Porto Alegre: Artes Médicas, 1994.

FODOR, Jerry A. The modularity of mind. Cambridge, MASS: MIT Press, 1983.

GLEASON, J. Berko, RATNER, N. B. (Ed.) Psycholinguistics. New York: Harcourt Brace Jovanovich, 1993.

KLEIMAN, Angela. Texto e leitor: aspectos cognitivos da leitura. Campinas: Pontes, 1989.

LABOV, W., VALETSKY, Y. Narrative Analysis: oral versions of personal experience. In: HELM, J. (Ed.) Essays on the verbal and visual arts. Seattle: Washington University Press, 1967.

LOBATO, Carmen H. M. Hipóteses de leitura: uma experiência com protocolo verbal. In: Congresso de Leitura, 9, 1993. (Mimeogr.). 
LOBATO, Carmen H. M. Leitura no segundo grau: a apropriação como processo de construção da macroestrutura do texto. Campinas: IEL/Unicamp, 1995. (Dissertação, Mestrado em Lingüística Aplicada)

MITCHELL, Don C. Reading and syntactic analysis. In: BEECH, J., COLLEY, A. (Ed.s). Cognitive approaches reading. New York: John Siley, 1987. p.87-112.

RUMELHART, D. E. Schemata: the building blocks of cognition. In: SPIRO et al. (Org. ${ }^{5}$ ) Theoretical Issues in Reading Comprehension. New Jersey: L. Erlbaum, 1980. p. 33-58.

TERZI, Sylvia B. A construção da leitura: uma experiência com crianças de meios iletrados. Campinas: Pontes, 1995.

VAN DIJK, Teun A., KINTSCH, Walter. Strategies of discourse comprehension. New York: Academic Press, 1983.

VAN DIJK, Teun A. Estrutura da notícia na imprensa. In: VAN DIJK, T. Discurso, cognição, interação. São Paulo: Contexto, 1992a. p.158-181.

VAN EEMEREN, T. A., GROOTENDORST, R. Speech acts in argumentative discussions. Dordrecht: Fons, 1984.

WALTY, Ivete Lara Camargos. Os sentidos da leitura. Presença pedagógica. Belo Horizonte: Dimensão, v.1, n. 4, jul./ago., 1995. p.26-33.

WINGFIELD, A. Sentence processing. In: BERKO GLEASON, J., RATNER, N. B. (Eds.) Psycholinguistics. New York: Harcourt Brace Jovanovich, 1993. p.200235. 